\title{
The Relationship of Carotid Plaque, Intima Media Thickness (IMT), Resistivity Index (RI) and Pulsatility Index (PI) in Asian-Indian Patients with Acute Ischemic Stroke with and without Type 2 DM
}

\author{
Sidhartha Das*, Kamalesh Chakrabarty, Madhusmita Patnaik, Laxmidhar Roul, Jayashree Mohanty, \\ Sarat Chandra Singh
}

Postgraduate Department of Medicine, Sriram Chandra Bhanj Medical College, Cuttack, India.

Email: *drsidhartha.cuttack@gmail.com

Received September $2^{\text {nd }}, 2011$; revised October $12^{\text {th }}, 2011$; accepted October $30^{\text {th }}, 2011$.

\begin{abstract}
Aim: To determine the relationship of carotid plaque, intima media thickness (IMT), resistivity index (RI) and pulsatility index $(P I)$ and prevalence of different risk factors with acute ischemic stroke and stroke subtypes in both diabetic and non-diabetic subjects. Materials and Methods: 80 cases of acute ischemic strokes and 40 healthy controls were included in the study. The plaque, IMT, RI and PI were measured by carotid duplex ultrasound. Results: 31 subjects were Type 2 diabetic, 54 hypertensive while 25 were both diabetic and hypertensive. 23 cases (28.75\%) had lacunar stroke (LACI), 32 (40\%) stroke involving partial anterior circulation (PACI), 10 (12.5\%) stroke in posterior circulation (PACI) and 15 (18.75\%) stroke involving total anterior circulation (TACI) respectively. The mean IMT(0.88 $\pm 0.19 \mathrm{~mm})$, $R I(0.76 \pm 0.05)$ and $P I(1.71 \pm 0.19)$ of patients and mean IMT $(0.6 \pm 0.09 \mathrm{~mm}), R I(0.61 \pm 0.06)$ and $P I(1.53 \pm 0.11)$ of controls were statistically significant ( $p$-0.000). The mean values of IMT, PI and RI were significantly higher in diabetics (IMT-0.90 \pm 0.16 vs $0.64 \pm 0.11, p-0.013 ; P I-1.76 \pm 0.20$ vs $1.49 \pm 0.09, p-0.000$ and RI-0.76 \pm 0.04 vs $0.59 \pm 0.06$, $P-0.000)$ and similarly the mean values for IMT, PI and RI in hypertensives as compared to controls (IMT-0.88 \pm 0.16 vs $0.65 \pm 0.10, p-0.006$; PI $1.69 \pm 0.18$ vs $1.49 \pm 0.09, p-0.000$ and $R I 0.76 \pm 0.04$ vs $0.59 \pm 0.06, p-0.000)$. The mean IMT, PI and RI were increased significantly in smokers compared to controls (IMT-0.93 \pm 0.20 vs $0.63 \pm 0.06, p-0.000$; $P I-1.82 \pm 0.22$ vs $1.49 \pm 0.09, p-0.000$ and $R I-0.77 \pm 0.04$ vs $0.59 \pm 0.06, p-0.000)$. Type 3 plaque accounted for 27 (56.2\%) cases and Type 2 plaque 12 (25\%) cases. The total number of plaques in patients as compared to controls were significantly more ( $p$-0.0034) and the mean plaque area was $46 \mathrm{~mm}^{2}$ for cases and $20 \mathrm{~mm}^{2}$ for control ( $p$-0.0001). TACI was the most common type of ischemic stroke seen in DM (60\%), HTN (66.6\%) and smokers (66.7\%). Plaques (73.3\%), $I M T(0.90 \pm 0.12), P I(1.72 \pm 0.14)$ and $R I(0.76 \pm 0.13)$ were more commonly associated with TACI subtype. On multivariate analysis using ANOVA, the mean PI was highly significant $(0.000)$ in relation to types of plaque. Summary and Conclusions: IMT, RI, PI and plaque type are useful diagnostic parameters for acute ischemic stroke and its subtypes. They can be used as noninvasive tools for predicting and preventing ischemic stroke in smokers as well as subjects with DM and hypertension.
\end{abstract}

Keywords: Intima Medial Thickness, Pulsatility Index, Resistivity Index, Carotid Plaque, Type 2 Diabetes Mellitus, Ischemic Stroke and Asian Indian Subjects

\section{Introduction}

Stroke is a global health problem [1,2]. Of 35 million deaths attributable to chronic non communicable diseases that occurred worldwide in 2005, stroke was responsible for 5.7 million (16.6\%) deaths, and $87 \%$ of these deaths occurred in low-income and middle-income counties [3].
Forty percent of stroke deaths occurred in people below 70 years of age [4,5]. Globally, approximately 15 million new acute stroke events occur every year, and approximately 55 million people have suffered from an event of stroke in the past. Two thirds of these individuals live in low- and middle-income countries such as India [6]. Driven by increase in the size of aging populations, and 
escalating prevalence of risk factors such as hypertension, tobacco use, unhealthy diet, physical inactivity, and obesity, stroke is becoming a major cause of premature death and disability in developing countries [7]. By 2050, it is anticipated that, $80 \%$ of stroke events will occur in people living in these regions [4,8]. Pathologically, the two major types of stroke are ischemic $(70 \%-80 \%)$ and hemorrhagic. Atherothrombotic occlusion of cerebral vessels is the major causes of ischemic stroke. Atherothrombotic strokes are consequent to generalized atherosclerosis $[9,10]$. Modifiable risk factors like diabetes, hypertension, smoking, dyslipidemia contribute to atherosclerosis through gradual changes in the arterial channels that may produce ischemia by either progressive luminal narrowing, or more commonly by sudden plaque rupture or intimal erosions with formation of an in situ occlusive thrombus [10,11].

The ability to identify persons with atherosclerosis and quantify the extent of atherosclerosis is of great value in stratifying the future risk for cardiovascular diseases and also for monitoring ongoing treatment. B-mode ultrasound is a noninvasive method for examining the walls of peripheral arteries and provides measures of intimamedia thickness (IMT), presence of stenosis, plaques and other changes in the vascular lumen as well as its wall. This procedure is widely accepted, safe, inexpensive, reliable, reproducible and convenient marker of atherosclerosis [12-15]. IMT is defined as the distance between blood-intima interface and media-adventitia interface of carotid wall [16]. IMT is $91 \%$ to $94 \%$ sensitive and $85 \%$ to $99 \%$ specific in detecting a significant stenosis of carotid artery [17]. The IMT corresponds to the intima-media complex, which comprises endothelial cells, connective tissue, and smooth muscle and is the site of lipid deposition in plaque formation [17]. IMT is made up of about $80 \%$ media and $20 \%$ intima, whereas atherosclerosis is largely an intimal process. IMT and plaques are highly intercorrelated [18,19]. IMT usually has been measured in the common carotid artery (CCA) because high measurement precision is easily obtained from this artery. However, plaques in this arterial segment are rare. Plaques usually occur at sites of non-laminar turbulent flow, such as in the carotid bulb and the proximal internal carotid artery (ICA) [20]. In healthy adults, IMT ranges from 0.25 to $1.5 \mathrm{~mm}$ and values more than $1.0 \mathrm{~mm}$ are often regarded as abnormal [21,22]. The plaque is defined as a focal thickening of $50 \%$ greater than the surrounding area or greater than $1.5 \mathrm{~mm}$ [12]. Plaque characteristics as well as vulnerable plaques can be assessed by ultrasound. Carotid plaques can be assessed qualitatively (plaque echogenicity, plaque heterogeneity) and quantitatively (plaque numbers, plaque area, plaque volume) [23]. Plaque area may therefore be a more sensitive and representative measure of the atherosclerotic burden than plaque thickness or IMT. Total carotid plaque area is also a stronger predictor of events than IMT but IMT measurements provide information on risk even when no plaque is present $[24,25]$. IMT of the carotid artery is a sonographic parameter that depends on the degree of atherosclerosis and it has been shown that CCA-IMT is a good predictor of stroke incidence, especially atherosclerotic non-lacunar subtype [14,15,26-28]. The pulsatility index (PI), which is calculated from the measured flow velocity by Doppler ultrasonography has been reported to increase with DM, old age, hypertension, intracranial hypertension, vascular dementia, and small artery disease $[27,28]$. The PI is a reflection of the vascular resistance distal to the examined artery. Therefore, the pathologies of small intracranial perforating arteries may affect the PI of the proximal artery so, may be better than IMT for predicting cerebral infarction. Thus, it is conceivable that the PI and resistive index (RI) of the common carotid artery may also be surrogate markers of atherosclerosis in cerebral arteries [27,29]. RI, a hemodynamic parameter that can be easily determined by Doppler sonography, reflects local wall extensibility and the related vascular resistance $[4,30]$. There is a clear correlation between increasing RI values and arteriosclerosis risk factors and clinical outcome [30].

\section{Materials and Methods}

This study was conducted in the Postgraduate Department of Medicine, S.C.B. Medical College and Hospital, Cuttack. Those patients who had associated hemorrhage along with a infarct, cases with embolic stroke (rheumatic heart disease, congenital heart disease and endocarditis),all cases of endarteritis and arteritis, coagulation disorders, sickle cell disease, CNS vasculitis and sub arachnoid hemorrhage were excluded from the study. After exclusion, 80 cases of ischemic strokes were included in the study and 40 cases of healthy, age matched persons were taken as control. Detailed history taking, clinical examination, routine blood chemistry, ECG, cervical carotid Doppler and CT scan of brain were undertaken for patients, while all procedure except CT scan of brain was done for controls. A plaque was defined as a focal thickening of $50 \%$ greater than the surrounding area or greater than $1.5 \mathrm{~mm}$. They were classified in to 5 types: type 1 -for normal or no observable plaque; type 2-for one small plaque with diameter stenosis $<30 \%$; type $3-$ for one medium plaque with $30 \%$ to $49 \%$ diameter stenosis or multiple small plaques; type 4-for one large plaque with $50 \%$ to $99 \%$ diameter stenosis or multiple plaques with at least one medium plaque; and type 5 for 
$100 \%$ occlusion [12].

The data were analyzed using the SPSS 16 software.

\section{Observations}

The mean age for cases was 64.82 years \pm 10.66 years. Mean age for male was 66.16 years \pm 10.7 years while for female $61.62 \pm 9.8$ years respectively. Out of 80 cases, 31 (38.75\%) were diabetic, 54 (67.5\%) hypertensive, 25 (31.25\%) were both diabetic and hypertensive, 49 (61.25\%) were smokers respectively. Similarly, 23 cases (28.75\%) had lacunar anterior cerebral infarction (LACI), 32 (40\%) had a stroke involving partial anterior circulation (PACI), $10(12.5 \%)$ had stroke in the posterior circulation (POCI) and $15(18.75 \%)$ had a stroke involving total anterior circulation (TACI) (Figure 1). The mean IMT $(0.88 \mathrm{~mm}$ $\pm 0.19 \mathrm{~mm})$, RI $(0.76 \pm 0.05)$ and PI $(1.71 \pm 0.19)$ of cases and mean IMT $(0.6 \mathrm{~mm} \pm 0.09 \mathrm{~mm})$, RI $(0.61 \pm$ $0.06)$ and PI (1.53 \pm 0.11$)$ of control groups was statistically significant. (p-0.000) (Table 1). In this study, the mean IMT, PI and RI for diabetics in case group was $0.90 \mathrm{~mm} \pm 0.16 \mathrm{~mm}, 1.76 \mathrm{~mm} \pm 0.20 \mathrm{~mm}$ and $0.76 \pm$ 0.04 and that for control group was $0.64 \pm 0.11 \mathrm{~mm}$ (p-0.013), $1.49 \pm 0.09(0.000)$ and $0.59 \pm 0.06(0.000)$ respectively. For patient with hypertension mean IMT $(0.88 \pm 0.16)$, PI $(1.69 \pm 0.18)$ and RI $(0.76 \pm 0.04)$ as compared to the control group mean IMT $0.65 \pm 0.10$ $\mathrm{mm}$ (p-0.006), PI $1.49 \pm 0.09$ (0.000) and RI $0.59 \pm 0.06$ (0.000). The mean IMT, PI and RI in smokers in cases group was $0.93 \mathrm{~mm} \pm 0.20 \mathrm{~mm}, 1.82 \pm 0.22 \mathrm{~mm}$ and $0.77 \mathrm{~mm} \pm 0.04 \mathrm{~mm}$ as compared to IMT $(0.63 \mathrm{~mm} \pm$ $0.06 \mathrm{~mm})$, PI (1.49 \pm 0.09$)$ and RI (0.59 \pm 0.06$)$ in control groups (p-000) (Table 1). Type 3 plaques accounted for 27 (56.2\%) cases and Type 2 plaque 12 (25\%) cases. The total no. of plaques in cases and controls was statistically significant (P-0.0034). The mean plaque area was $46 \mathrm{~mm}^{2}$ for cases and $20 \mathrm{~mm}^{2}$ for control (P-0.0001). (Table 2) The mean IMT was higher in patient with plaque in comparison to patient without plaque, irrespective of gender, which was statistically significant. (Figure 2) Smokers were more common in TACI, PACI sub type. DM was more associated with TACI, where as HTN was associated with LACI, PACI, TACI. Plaque was more associated with TACI and PACI. Mean IMT was more in patient in POCI and TACI category, mean PI more in POCI and TACI and mean RI more in PACI and TACI (Table 3). On multivariate analysis using ANOVA, the mean PI was highly significant $(0.000)$ in relation to types of plaque (Table 4).

\section{Discussion}

In this study, the mean age for patients with stroke in males was $66.62 \mathrm{yr} \pm 10.7 \mathrm{yr}$ and for females $61.62 \mathrm{yr} \pm$ 9.8 yr. The average mean age was $64.82 \mathrm{yr} \pm 10.60 \mathrm{yr}$.
Earlier reports had shown similar age of incidence in patients with ischemic stroke [31,32]. The prevalence of risk factors in our study group was Type 2 diabetes mellitus (DM) in 38.75\%, hypertension (HTN) in 67.5\%, both DM and HTN in $31.25 \%$, smoking in $61.25 \%$ and $6.25 \%$ cases had no risk factors. These observations are at par with earlier publications $[1,31,32]$. In the present study, as per the Bamford classification of ischemic stroke, 23 cases (28.75\%) had (LACI), 32 (40\%) PACI, $10(12.5 \%)$ POCI and 15 (18.75\%) TACI which was consistent with other studies (Figure 1) [33]. The mean IMT $(0.88 \mathrm{~mm} \pm 0.19 \mathrm{~mm}), \mathrm{RI}(0.76 \pm 0.05)$ and PI (1.71 $\pm 0.19)$ of cases and mean IMT (0.6 mm $\pm 0.09 \mathrm{~mm})$, RI $(0.61 \pm 0.06)$ and PI $(1.53 \pm 0.11)$ of controls were statistically significant $(\mathrm{p}-0.000)$ as presented in Table 1. Such observations are at par with previous studies $[20,34,35]$. The mean IMT, PI and RI for diabetics was $0.90 \mathrm{~mm} \pm 0.16 \mathrm{~mm}, 1.76 \mathrm{~mm} \pm 0.20 \mathrm{~mm}$ and $0.76 \pm$ 0.04 and that for control group was $0.64 \mathrm{~mm} \pm 0.11 \mathrm{~mm}$ (p-0.013), $1.49 \pm 0.09$ (p-0.000) and $0.59 \pm 0.06$ (p-0.000) respectively. This observation was comparable with previous publication where the carotid-IMT was found to be $0.9 \mathrm{~mm}$ in DM [32,36]. For patient with hypertension, the mean IMT (0.88 \pm 0.16$), \operatorname{PI}(1.69 \pm 0.18)$ and $\mathrm{RI}(0.76$ $\pm 0.04)$ as compared with controls was highly significant

\section{TYPE OF STROKE BASED ON BAMFORD CLASSIFICATION}

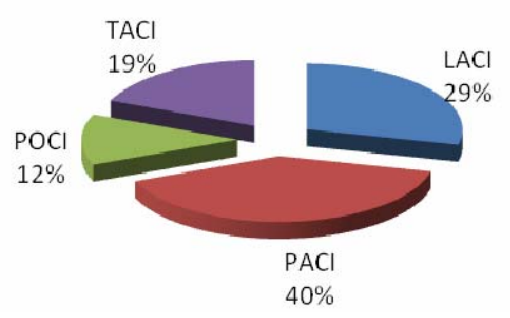

Figure 1. Prevalence of type of strokes (in percent).

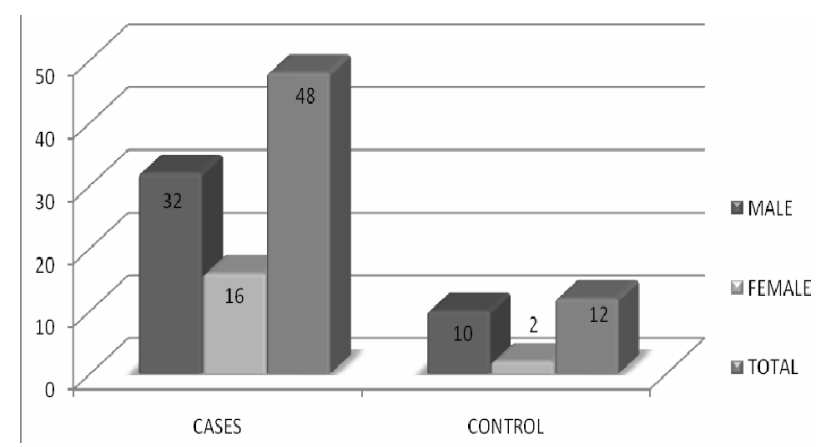

Figure 2. Prevalence of plaques in patients with Stroke and without stroke in male and female subjects. 
(Table 1). The mean IMT, PI and RI in smokers in patients was $0.93 \mathrm{~mm} \pm 0.20 \mathrm{~mm}, 1.82 \mathrm{~mm} \pm 0.22 \mathrm{~mm}$ and $0.77 \mathrm{~mm} \pm 0.04 \mathrm{~mm}$ as compared to $\operatorname{IMT}(0.63 \mathrm{~mm} \pm$ $0.06 \mathrm{~mm}), \mathrm{PI}(1.49 \pm 0.09)$ and $\mathrm{RI}(0.59 \pm 0.06)$ in control groups (p-000) (Table 1). Previous reports have shown that the mean IMT of persons having HTN, DM and in smokers was significantly higher than healthy people
[34].

Type 3 plaques accounted for 27 (56.2\%) cases and Type 2 plaque 12 (25\%) cases. The difference in total number of plaques in cases and controls was statistically significant (P-0.0034). The mean plaque area was 46 $\mathrm{mm}^{2}$ for cases and $20 \mathrm{~mm}^{2}$ for controls (p-0.0001) as given in Table 2.

Table 1. Mean values of IMT, RI and PI in patients and controls along with statistical significance of difference.

\begin{tabular}{|c|c|c|c|}
\hline Imt in mm & Cases & Control & p-VALUE \\
\hline OVERALL MEAN IMT & $0.88 \pm 0.19(\mathrm{~N}=80)$ & $0.60 \pm 0.09(\mathrm{~N}=40)$ & 0.000 \\
\hline IMT IN DIABETES & $0.90 \pm 0.16(\mathrm{~N}=31)$ & $0.64 \pm 0.11(\mathrm{~N}=14)$ & 0.013 \\
\hline IMT IN HTN & $0.88 \pm 0.16(\mathrm{~N}=53)$ & $0.65 \pm 0.10(\mathrm{~N}=14)$ & 0.006 \\
\hline IMT IN SMOKERS & $0.93 \pm 0.20(\mathrm{~N}=49)$ & $0.63 \pm 0.06(\mathrm{~N}=17)$ & 0.000 \\
\hline PI in $\mathbf{m m}$ & CASES & CONTROL & p-VALUE \\
\hline OVERALL MEAN PI & $1.71 \pm 0.18 \mathrm{~mm}(\mathrm{~N}=80)$ & $1.53 \pm 0.11(\mathrm{~N}=40)$ & 0.000 \\
\hline PI IN DIABETES & $1.76 \pm 0.20 \mathrm{~mm}(\mathrm{~N}=31)$ & $1.49 \pm 0.09(\mathrm{~N}=18)$ & 0.000 \\
\hline PI IN HTN & $1.69 \pm 0.18 \mathrm{~mm}(\mathrm{~N}=53)$ & $1.49 \pm 0.09(\mathrm{~N}=18)$ & 0.000 \\
\hline PI IN SMOKERS & $1.82 \pm 0.22(\mathrm{~N}=49)$ & $1.49 \pm 0.09(\mathrm{~N}=18)$ & 0.000 \\
\hline $\mathrm{Ri}$ in $\mathbf{m m}$ & Cases & Control & p-VALUE \\
\hline OVERALL MEAN RI & $0.76 \pm 0.05(\mathrm{~N}=80)$ & $0.61 \pm 0.06(\mathrm{~N}=40)$ & 0.000 \\
\hline RI IN DIABETES & $0.76 \pm 0.04(\mathrm{~N}=31)$ & $0.59 \pm 0.06(\mathrm{~N}=18)$ & 0.000 \\
\hline RI IN HTN & $0.76 \pm 0.04(\mathrm{~N}=53)$ & $0.59 \pm 0.06(\mathrm{~N}=18)$ & 0.000 \\
\hline RI IN SMOKERS & $0.77 \pm 0.04(\mathrm{~N}=49)$ & $0.59 \pm 0.06(\mathrm{~N}=18)$ & 0.000 \\
\hline
\end{tabular}

Table 2. Plaque characteristic in patients and controls.

\begin{tabular}{|c|c|c|c|c|}
\hline Characteristics & & Cases (n-48) & Control (n-12) & p-VALUE \\
\hline \multirow{5}{*}{ TYPE OF PLAQUE } & 1 & 0 & 0 & \multirow{5}{*}{0.0034} \\
\hline & 2 & $12(25 \%)$ & $6(50 \%)$ & \\
\hline & & & & \\
\hline & 3 & $27(56.2 \%)$ & $6(50 \%)$ & \\
\hline & 4 & $9(18.8 \%)$ & 0 & \\
\hline PLAQUE AREA $\left(\mathrm{mm}_{2}\right)$ & & $46(18-84)$ & $20(8-26)$ & 0.0001 \\
\hline
\end{tabular}


The mean IMT was higher in patient with plaque in comparison to patient without plaque, irrespective of gender, which was statistically significant (Table $\mathbf{1}$ and Figure 2) and was comparable with other study [35]. On comparison between subtypes of stroke, prevalence of smokers was more in TACI (66.7\%), PACI (65.5\%) sub types whereas DM was more associated with TACI (60\%), and HTN with LACI (69.6\%), PACI (68.8\%), TACI (66.7\%) respectively as presented in Table 3. Plaque was more often met with TACI (73.3\%) and PACI (65.5\%) than other types of ischemic stroke. Mean IMT was more in patient with POCI $(0.93 \pm 0.27)$ and TACI $(0.90 \pm 0.12)$ category, mean PI more in POCI $(1.76 \pm 0.31)$ and TACI $(1.72 \pm 0.14)$ and mean RI more in PACI $(0.77 \pm 0.05)$ and TACI $(0.76 \pm 0.13)$ which was comparable with earlier studies [35]. The study had reported a prevalence of HTN in $80 \%$ of PACI, DM in $40 \%$ of TACI and plaques in $85 \%$ of PACI and $79 \%$ of LACI [35]. On multivariate analysis using ANOVA, the mean PI was highly significant $(\mathrm{p}-0.000)$ in relation to types of plaque.
As observed in the present sstudy PI may be better than IMT for predicting cerebral infarction.

\section{Summary and Conclusions}

Our study revealed $75 \%$ of cases were above 60 years of age and the prevalence of risk factors like DM was present in 38\%, HTN in 67\%, and smoking in 61\% respecttively. According to Bamford classification, 28\% had LACI, $40 \%$ had PACI, $12 \%$ had POCI and 18\% had TACI. The mean IMT for DM, HTN and smokers were higher than the control groups. The mean IMT, PI and RI in patients with DM, HTN and in smokers were significantly higher than the controls. The mean IMT was higher in patient with plaque in comparison to patient without plaque, irrespective of gender. Type 3 plaque accounted for 27 (56.2\%) and Type 2 plaque in 12 (25\%) of cases with ischemic stroke. The total no. of plaques in cases and controls was statistically significant and the mean plaque area was $46 \mathrm{~mm}^{2}$ for cases and $20 \mathrm{~mm}^{2}$ for controls. The mean PI was highly significant (0.000) in relation to types of plaque. As per the study, PI may be better than IMT for predicting cerebral infarction.

Table 3. Risk factors, IMT, PI, RI and plaques in patients with different subtypes of stroke.

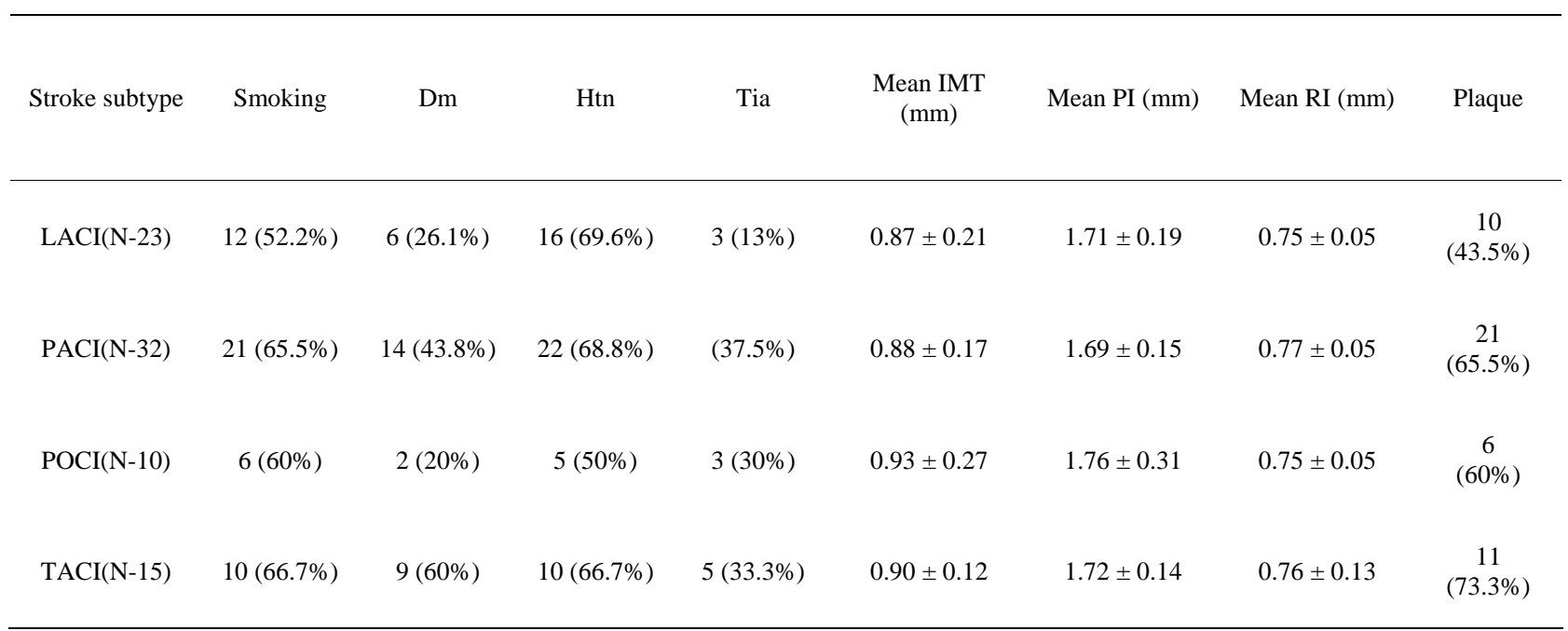

Table 4. Mean values of IMT, PI, RI in different subtype of plaques.

\begin{tabular}{|c|c|c|c|c|c|c|c|c|}
\hline & Type 1 & Type 2 & Type 3 & Type 4 & 2 vs 3 & 2 vs 4 & 3 vs 4 & ANOVA \\
\hline MEAN IMT & - & $0.93 \pm 0.17$ & $0.89 \pm 0.12$ & $0.92 \pm 0.29$ & 0.40 & 0.92 & 0.66 & 0.77 \\
\hline MEAN PI & - & $1.68 \pm 0.14$ & $1.76 \pm 0.19$ & $1.64 \pm 0.17$ & 0.28 & 0.000 & 0.000 & 0.000 \\
\hline MEAN RI & - & $0.77 \pm 0.04$ & $0.77 \pm 0.04$ & $0.75 \pm 0.04$ & 0.99 & 0.33 & 0.22 & 0.45 \\
\hline
\end{tabular}


Therefore, an increased IMT, RI, PI and/or plaques on carotid duplex ultrasound are dependable surrogate markers of cerebrovascular ischemic events. They can be used as noninvasive tools for predicting and preventing ischemic stroke in smokers as well as subjects with DM and hypertension.

\section{Conflict of Interest}

This project was neither funded nor sponsored by agency or pharmaceutical firm. This original research work is part of the regular postgraduate research thesis work of the Postgraduate Department of Medicine. The authors undertake that there is no conflict of interest, whatso ever, with anyone.

\section{REFERENCES}

[1] S. E. Sridharan, J. P. Unnikrisnan, S. Sukumaran, P. N. Sylyja, S. D. Nayak, P. S. Sarma, et al., "Incidence, Types, Risk Factors, and Outcome of Stroke in a Developing Country: The Trivandrum Stroke Registry," Stroke, Vol. 40, No. 4, 2009, pp. 1212-1218. doi:10.1161/STROKEAHA.108.531293

[2] G. A. Donnan, M. Fisher, M. Macleod and S. M. Davis, “Stroke," Lancet, Vol. 371, 2008, pp. 1612-1623. doi:10.1016/S0140-6736(08)60694-7

[3] K. Strong, C. Mathers and R. Bonita, "Preventing Stroke: Saving Lives around the World," Lancet Neurology, Vol. 6, No. 2, 2007, pp. 182-187. doi:10.1016/S1474-4422(07)70031-5

[4] C. J. Murray and A. D. Lopez, "Alternative Projections of Mortality and Disability by Cause. 1990-2020: Global Burden of Disease Study,” Lancet, Vol. 349, No. 9064, 1997, pp. 1498-1504. doi:10.1016/S0140-6736(96)07492-2

[5] J. D. Pandian, V. Srikanth, S. J. Read and A. G. Thrift, "Poverty and Stroke in India: A Time to Act," Stroke, Vol. 38, No. 11, 2007, pp. 3063-3069. doi:10.1161/STROKEAHA.107.496869

[6] Indian Economy Overview, 2011. www.economywatch.com/indianeconomy/indian-economyoverview.html

[7] World Health Organization, "The World Health Report 2004: Changing History,” Geneva, WHO, 2004.

[8] V. L. Feigin, "Stroke in Developing Countries: Can the Epidemic Be Stopped and Outcomes Improved?” Lancet Neurology, Vol. 6, No. 2, 2007, pp. 94-97. doi:10.1016/S1474-4422(07)70007-8

[9] W. S. Smith, J. D. English and S. C. Johnston, "Cerebrovascular Disease," 17th Edition, Harrison's Principle of Internal Medicine, McGraw Hill \& Co., New York, 2008, pp. 2513-2535.

[10] D. A. De Silva, F. P. Woon, M. P. Lee, C. P. Chen, H. M. Chang and M. C. Wong, "South Asian Patients with Ischemic Stroke Intracranial Large Arteries Are the Pre- dominant Site of Disease,” Stroke, Vol. 38, No. 9, 2007, pp. 2592-2594. doi:10.1161/STROKEAHA.107.484584

[11] M. L. Eigenbrodt, Z. Brusac, R. E. Tracy, J. L. Meheta, K. M. Rose and D. J. Couper, "B-Mode Ultrasound Common Carotid Artery Intima-Media Thickness and External Diameter: Cross-Sectional and Longitudinal Associations with Carotid Atherosclerosis in a Large Population Sample,” Cardiovascular Ultrasound, Vol. 6, No. 10, 2008, pp. 10-16. doi:10.1186/1476-7120-6-10

[12] S. H. Johnsen and E. B. Mathiesen, "Carotid Plaque Compared with Intima-Media Thickness as a Predictor of Coronary and Cerebrovascular Disease," Current Cardiology Reports, Vol. 11, No. 1, 2009, pp. 21-27. doi:10.1007/s11886-009-0004-1

[13] G. Belcaro, A. N. Nicolaides, G. Laurora, M. R. Cesarone, M. De Sanctis, L. Incandela, et al., "Ultrasound Morphology Classification of the Arterial Wall and Cardiovascular Events in a 6-Year Follow-Up Study," Arteriosclerosis, Thrombosis, and Vascular Biology, Vol. 16, No. 7, 1996, pp. 851-856. doi:10.1161/01.ATV.16.7.851

[14] M. G. Veller, C. M. Fisher and A. N. Nicolaides, "Measurement of the Ultrasonic Intima-Media Complex Thickness in Normal Subjects," Journal of Vascular Surgery, Vol. 17, No. 4, 1993, pp. 719-725. doi:10.1016/0741-5214(93)90116-4

[15] S. Ebrahim, O. Papacosta, P. Whincup, G. Wannamethee, M. Walker, A. N. Nicolaides, et al., "Carotid Plaque, Intima Media Thickness, Cardiovascular Risk Factors, and Prevalent Cardiovascular Disease in Men and Women. The British Regional Heart Study,” Stroke, Vol. 30, 1999, pp. 841-850. doi:10.1161/01.STR.30.4.841

[16] K. Potter, C. J. Reed, D. J. Green, G. J. Hankey and L. F. Arnolda, "Ultrasound Settings Significantly Alter Arterial Lumen and Wall Thickness Measurements," Cardiovascular Ultrasound, Vol. 6, No. 6, 2008, pp. 1-6.

[17] J. T. Salonen and R. Salonen, "Ultrasound B-Mode Imaging in Observational Studies of Atherosclerotic Progression,” Circulation, Vol. 87, Supplement 2, 1993, pp. 56-65.

[18] C. Bonithon-Kopp, P. J. Touboul and C. Berr, "Relation of Intima-Media Thickness to Atherosclerotic Plaques in Carotid Arteries. The Vascular Aging (EVA) Study," Arteriosclerosis, Thrombosis, and Vascular Biology, Vol. 16, 1996, pp. 310-316. doi:10.1161/01.ATV.16.2.310

[19] M. L. Bots, A. Hofman, P. T. De Jong and D. E. Grobbee, "Common Carotid Intima-Media Thickness as an Indicator of Atherosclerosis at Other Sites of the Carotid Artery. The Rotterdam Study," Annals of Epidemiology, Vol. 6, No. 2, 1996, pp. 147-153. doi:10.1016/1047-2797(96)00001-4

[20] S. Glagov, C. Zarins, D. P. Giddens and D. N. Ku, "Hemodynamics and Atherosclerosis. Insights and Perspectives Gained from Studies of Human Arteries," Archives of Pathology \& Laboratory Medicine, Vol. 112, 1988, pp. 1018-1031.

[21] P. M. Dalal, "Studies in Young and Elderly: Risk Factors 
and Strategies for Stroke Prevention,” Journal of the Association of Physicians of India, Vol. 45, 1997, pp. 125131.

[22] P. M. Dalal and M. Bhattacharjee, "Stroke Epidemic in India: Hypertension-Stroke Control Programme Is Urgently Needed," Journal of the Association of Physicians of India, Vol. 55, 2007, pp. 689-691.

[23] P. A. Barnett, J. D. Spence, S. B. Manuck and J. R. Jennings, "Psychological Stress and the Progression of Carotid Artery Disease," Journal of Hypertension, Vol. 15, 1997, pp. 49-55. doi:10.1097/00004872-199715010-00004

[24] J. D. Spence, M. Eliasziw, M. DiCicco, G. D. Hackam, R. Galil and T. Lohmann, "Carotid Plaque Area: A Tool for Targeting and Evaluating Vascular Preventive Therapy," Stroke, Vol. 33, 2002, pp. 2916-2922. doi:10.1161/01.STR.0000042207.16156.B9

[25] L. M. Cupini, P. Pasqualetti, M. Diomedi, F. Vernieri, M. Silvestrini, B. Rizzato, et al., "Carotid Artery Intimamedia Thickness and Lacunar versus Nonlacunar Infarcts," Stroke, Vol. 33, No. 3, 2002, pp. 689-694. doi:10.1161/hs0302.103661

[26] D. H. O’Leary, J. F. Polak, R. A. Kronmal, T. A. Manolio, G. L. Burke and S. K. Wolfson, "Carotid-Artery Intima and Media Thickness as a Risk Factor for Myocardial Infarction and Stroke in Older Adults," New England Journal of Medicine, Vol. 340, No. 1, 1999, pp. 14-22. doi:10.1056/NEJM199901073400103

[27] T. Fukuhara and K. Hida, "Pulsatility Index at the Cervical Internal Carotid Artery as Parameter of Microangiopathy in Patients with Type 2 Diabetes," Journal of Ultrasound in Medicine, Vol. 25, No. 5, 2006, pp. 599605.

[28] K. Y. Lee, Y. H. Sohn, J. S. Baik, G. W. Kim and J. S. Kim, "Arterial Pulsatility as an Index of Cerebral Microangiopathy in Diabetes,” Stroke, Vol. 31, No. 5, 2000, pp. 1111-1115. doi:10.1161/01.STR.31.5.1111

[29] K. O. Lee, K. Y. Lee, Y. S. Lee, C. W. Ahn and J. S. Park, "Lacunar Infarction in Type 2 Diabetes Is Associated with an Elevated Intracranial Arterial Pulsatility Index,” Yonsei Medical Journal, Vol. 48, No. 5, 2007, pp. 802 806. doi:10.3349/ymj.2007.48.5.802

[30] D. Staub, A. Meyerhans, B. Bundi, H. P. Schmid and B. Frauchiger, "Prediction of Cardiovascular Morbidity and Mortality: Comparison of the Internal Carotid Artery Resistive Index with the Common Carotid Artery Intima-Media Thickness,” Stroke, Vol. 37, 2006, pp. 800805. doi:10.1161/01.STR.0000202589.47401.c6

[31] D. Nagaraja, G. Gururaj, N. Girish, S. Panda, A. K. Roy, G. R. K. Sarma, et al., "Feasibility Study of Stroke Surveillance: Data from Bangalore, India,” Indian Journal of Medical Research, Vol. 130, No. 4, 2009, pp. 396-403.

[32] T. Nakatou, K. Nakata, A. Nakamura and T. Itoshima, "Carotid Haemodynamic Parameters as a Risk Factors in Type2 Diabetic Patients,” Diabetic Medicine, Vol. 21, 2004, pp. 223-229. doi:10.1111/j.1464-5491.2004.01108.x

[33] R. Sahoo, M. V. Krishna, D. K. S. Subrahmaniyan, T. K. Dutta and S. Elangovan, "Common Carotid Intima-Media Thickness in Acute Ischemic Stroke: A Case Control Study," Neurology India, Vol. 57, No. 5, 2009, pp. 627630. doi:10.4103/0028-3886.57822

[34] J. Bamford, P. Sandercock, M. Dennis, J. Burn and C. Warlow, "Classification and Natural History of Clinically Identifiable Subtypes of Cerebral Infarction,” Lancet, Vol. 337, 1991, pp. 1521-1526. doi:10.1016/0140-6736(91)93206-O

[35] B. Frauchiger, H. P. Schmid, C. Roedel, P. Moosmann and D. Staub, "Comparison of Carotid Arterial Resistive Indices with Intima-Media Thickness as Sonographic Markers of Atherosclerosis,” Stroke, Vol. 32, 2001, pp. 836-841. doi:10.1161/01.STR.32.4.836

[36] P. Nikic, M. Savic, V. Jakovljevic and D. Djuric, “Carotid Atherosclerosis, Coronary Atherosclerosis and Carotid Intima-Media Thickness in Patients with Ischemic Cerebral Disease: Is There Any Link?” Experimental \& Clinical Cardiology, Vol. 11, No. 2, 2006, pp. 102-106. 